NBER WORKING PAPER SERIES

THE HOUSEHOLD FALLACY

\author{
Roger Farmer \\ Pawel Zabczyk \\ Working Paper 24393 \\ http://www.nber.org/papers/w24393
}

\author{
NATIONAL BUREAU OF ECONOMIC RESEARCH \\ 1050 Massachusetts Avenue \\ Cambridge, MA 02138 \\ March 2018
}

We would like to thank, without implicating, seminar participants at the Bank of England, Deutsche Bundesbank, Glasgow University and Narodowy Bank Polski. The views expressed herein are those of the authors and do not necessarily reflect the views of the National Bureau of Economic Research.

NBER working papers are circulated for discussion and comment purposes. They have not been peer-reviewed or been subject to the review by the NBER Board of Directors that accompanies official NBER publications.

(C) 2018 by Roger Farmer and Pawel Zabczyk. All rights reserved. Short sections of text, not to exceed two paragraphs, may be quoted without explicit permission provided that full credit, including $(\odot$ notice, is given to the source. 
The Household Fallacy

Roger Farmer and Pawel Zabczyk

NBER Working Paper No. 24393

March 2018

JEL No. E0,H62

\begin{abstract}
$\underline{\text { ABSTRACT }}$
We refer to the idea that government must 'tighten its belt' as a necessary policy response to higher indebtedness as the household fallacy. We provide a reason to be skeptical of this claim that holds even if the economy always operates at full employment and all markets clear. Our argument rests on the fact that, in an overlapping-generations (OLG) model, changes in government debt cause changes in the real interest rate that redistribute the burden of repayment across generations. We do not rely on the assumption that the equilibrium is dynamically inefficient, and our argument holds in a version of the OLG model where the real interest rate is always positive.
\end{abstract}

\author{
Roger Farmer \\ UCLA \\ Department of Economics \\ Box 951477 \\ Los Angeles, CA 90095-1477 \\ and CEPR \\ and also NBER \\ rfarmer@econ.ucla.edu \\ Pawel Zabczyk \\ Centre for Central Bank Studies HO7 B-D \\ Bank of England \\ Threadneedle Street EC2R 8AH, \\ London, UK \\ pawel@zabczyk.com
}




\title{
THE HOUSEHOLD FALLACY*
}

\author{
ROGER E.A. FARMER AND PAWEL ZABCZYK
}

This version March 2, 2018

In the midst of the Great Recession, John Boehner, former speaker of the U.S. House of Representatives, stated that it's time for government to tighten their belts and show the American people that we 'get it' (CBS News' Face the Nation, March 2, 2009). This argument has popular appeal with the average person who is familiar with the concept of budgeting in his or her everyday life. But the idea that government too must 'tighten its belt' as a necessary policy response to higher indebtedness is what we call the household fallacy.

The 'belt tightening' view has been widely criticized by a group of journalists and academic economists, most notably Martin Wolf (2013) and Paul Krugman (2015). Wolf and Krugman used arguments based on Keynesian economics to claim that austerity, reducing government spending or increasing taxes, was the wrong policy response to the Great Recession 1 They argued that the level of employment is often inefficiently low, and that fiscal stimulus in a recession can reduce inefficient levels of unemployment and generate sufficient new tax revenues to pay for itself.

We provide a different reason to be skeptical of the claim that fiscal deficits must be actively adjusted to repay outstanding debt. Our results hold even if the economy always operates at full employment and all markets clear. They rest on the fact that, in an overlappinggenerations (OLG) model, changes in government debt cause changes in the real interest rate that redistribute the burden of repayment across generations. The interest rate adjustments that generate this redistribution arise under standard assumptions about utility and endowments but are assumed away in the workhorse representative agent (RA) model. Our argument does not rely on the assumption that the equilibrium is dynamically inefficient and it holds in a version of the OLG model where the real interest rate is always positive.

\footnotetext{
* We would like to thank, without implicating, seminar participants at the Bank of England, Deutsche Bundesbank, Glasgow University and Narodowy Bank Polski.

${ }^{1}$ For an updated version of the Keynesian argument see Eggertsson and Krugman (2012) and for an alternative reinterpretation of The General Theory with different policy implications, see Farmer (2012).
} 


\section{Why Government Debt is Different: Debunking the Fallacy}

Governments are monopoly suppliers of risk-free treasury securities. In contrast to households, which are assumed to be price-takers, government debt-management policies have firstorder implications for the interest rate. We show that an increase in government debt can, under plausible parameterizations of the economy, cause a drop in the real interest rate. As a consequence, the fiscal authority can run an active policy that ignores the level of debt when determining the path of the primary fiscal deficit ${ }^{2}$ To make this point formally, we use a twogeneration overlapping generations model. The key to our result is that the agents who hold government debt are distinct from those who repay it through higher taxes.$^{3}$

1.1. The Supply of Government Bonds. Consider a government which purchases $g_{t}$ units of a consumption good in period $t$, financed from lump-sum taxation $\tau_{t}$ and from the sale of one period pure discount bonds. A bond issued at date $t$ is a claim on consumption goods at date $t+1$ and we use the symbol $b_{t+1}$ to denote the number of these bonds issued at date $t$. Let $R_{t+1}$ be the real interest factor from $t$ to $t+1$ and let $1 / R_{t+1}$ denote the date $t$ price of the bond. The one-period government budget constraint is given by the expression,

$$
\frac{b_{t+1}}{R_{t+1}}+\tau_{t}=b_{t}+g_{t}, \text { for all } t
$$

Let $d_{t}$, defined as,

$$
d_{t} \equiv g_{t}-\tau_{t}
$$

be the primary fiscal deficit, with negative values of $d_{t}$ denoting a surplus. Using this definition, we may rewrite Equation 1 governing the accumulation of government debt as,

$$
\forall t: \quad b_{t+1}=R_{t+1} \cdot\left(b_{t}+d_{t}\right) .
$$

1.2. The Demand for Government Bonds. Every period, the young receive an after tax endowment of 1 unit of the consumption good and the old receive an after tax endowment of $w^{2} \geq 0$ units of the consumption good 4 Using the convention that a superscript denotes the

\footnotetext{
${ }^{2}$ Leeper (1991) refers to a fiscal policy as active if taxation and expenditure are independent of the path of real interest rates.

${ }^{3}$ The two-period overlapping generations model has been extensively used in the literature. See, for example, Gale (1973); Cass et al. (1979); Balasko and Shell (1981); Grandmont (1985) and Geanakoplos and Polemarchakis (1991). Gourieroux et al. (1982) and Azariadis and Guesnerie (1986) study stochastic extensions, while Diamond (1965) replaces government debt with capital as the sole investment opportunity. Farmer and Zabczyk (2018) show that the same mechanism that allows fiscal policy to be 'active' in the model is also present in a carefully calibrated setup featuring 70 cohorts.

${ }^{4}$ Taxes are covered in more detail in Section A of a Technical Appendix that is available online.
} 
period of life and a subscript denotes calendar time, the saving of the young, $s_{t}^{1}$, is related to their consumption, $c_{t}^{1}$, by the identity,

$$
s_{t}^{1} \equiv 1-c_{t}^{1}
$$

and consumption in each period of life solves the following maximization problem,

$$
\begin{gathered}
\max _{c_{t}^{1}, c_{t+1}^{2}} \frac{\left(c_{t}^{1}\right)^{\alpha}+\beta\left(c_{t+1}^{2}\right)^{\alpha}-(1+\beta)}{\alpha}, \\
\text { s.t.: } c_{t}^{1}+\frac{c_{t+1}^{2}}{R_{t+1}}=1+\frac{w^{2}}{R_{t+1}} .
\end{gathered}
$$

Here, $\beta>0$ and $\alpha \leq 1$ are parameters, with the elasticity of intertemporal substitution given by $\eta \equiv 1 /(1-\alpha)$ and log-utility corresponding to $\alpha \rightarrow 0$. This problem has a closed-form solution for consumption, with the implied savings function of the young equal to,

$$
s^{1}\left(R_{t+1}\right) \equiv s_{t}^{1}=1-\frac{R_{t+1}^{1-\eta}+w^{2} R_{t+1}^{-\eta}}{R_{t+1}^{1-\eta}+\beta^{\eta}} .
$$

Since the old don't save, aggregate savings are equal to the savings of the young: $S\left(R_{t+1}\right) \equiv$ $s^{1}\left(R_{t+1}\right)$. For bond markets to clear, aggregate savings must equal the existing supply of government bonds $b_{t}$ plus a stock of new bonds issued (or retired) to cover the primary deficit $d_{t}$ (or surplus), i.e.

$$
\forall t: \quad S\left(R_{t+1}\right)=b_{t}+d_{t} .
$$

Crucially, Equation 5 establishes that whenever bond demand is less than infinitely elastic, i.e. as long as $S(\cdot)$ is not vertical, the market clearing real interest rate $R_{t+1}$ will depend on the stock of debt $b_{t}+d_{t}$ which the government has to refinance.

1.3. The Real Rate as an Automatic Stabilizer. Our full model comprises Equations 3 and 5 with initial condition $b_{1}=\bar{b}_{1}$. In what follows we limit attention to dynamics around steady states that satisfy the following two conditions.

Condition 1 (Active Fiscal Policy). The primary fiscal deficit $d_{t}$ is constant and negative

$$
\forall t: d_{t} \equiv d<0
$$

We further impose

Condition 2 (Dynamic Efficiency). There exists a date $t$ and a number $\epsilon>0$, such that

$$
\forall s \geq t: R_{s}>1+\epsilon .
$$


Condition 1 is meant to characterize fiscal policymakers, who, to paraphrase John Boehner, 'don't get it'. Specifically, they fail to adjust the size of the primary deficit $d$ in response to changes in economic conditions and the level of debt outstanding. We focus on this case to demonstrate that, contrary to those who argue for austerity to counteract a recession, an unresponsive fiscal policy need not result in explosive debt dynamics. In line with post-war US experience, we assume that $d$ is negative and hence the treasury runs a primary surplus 5

Condition 2 requires that the equilibrium real rate eventually becomes strictly positive. We make this assumption to rule out models with a negative interest rate in which the equilibrium is dynamically inefficient. It is well known that fiscal policy can be active in this case as a negative interest rate erodes the value of government debt.

Iterating on Equation 3, and imposing Condition 1 yields,

$$
b_{1}=\sum_{t=1}^{+\infty}\left(\frac{-d}{\prod_{\tau=2}^{t} R_{\tau}}\right)+\lim _{s \rightarrow+\infty} \frac{b_{s}}{\prod_{\tau=2}^{s} R_{\tau}} .
$$

Condition 2 ensures that the limiting term vanishes as long as debt $b_{s}$ does not explode. In any such equilibrium debt $b_{1}$ can be thus expressed as the NPV of future fiscal surpluses,

$$
b_{1}=\sum_{t=1}^{+\infty}\left(\frac{-d}{\prod_{\tau=2}^{t} R_{\tau}}\right) .
$$

As our starting point, we assume that the economy is in a perfect foresight equilibrium with some initial level of debt $\bar{b}_{1}$. The equilibrium assumption implies that the initial level of debt is related to the expected value of future surpluses by Equation 6. Next, we consider a thought experiment in which we increase the initial level of debt from $\bar{b}_{1}$ to some higher level $\bar{b}_{\text {new }}>\bar{b}_{1}$, say, due to unplanned government expenditure in support of the financial system. We ask if Equation 6 can continue to hold if the government continues to maintain a constant positive primary surplus, $-d$.

According to the household fallacy the answer is no. In the absence of austerity (i.e. falls in $d_{t}$ for some $t$ ) government debt inevitably spirals out of control, leading to a violation of Equation 6. The argument is a fallacy because it ignores the possibility of equilibrium real rates (the denominator) adjusting in response to the new initial condition. If there exists a path of $R_{s}$ under which Equation 6 holds for different values of $b_{1}$, then the fiscal authority can run active policy forever and the real rate dynamics prevents government debt from exploding.

5 Cochrane $(2018)$ shows that the US ran a primary surplus of approximately $2 \%$ of potential GDP in almost every year prior to the Great Recession. 
Because a lower path of real rates in response to a higher initial level of debt $b_{1}$ ensures debt stability, we refer to the real interest rate as an automatic stabilizer.

But why should equilibrium real rates respond this way to changes in initial conditions? Because the young are savers, and, if the stock of government debt is large, negative income effects associated with lower interest rates induce them to consume less and save more. In what follows we show that income effects are large enough under a credible calibration of our model for this case to be of practical relevance.

1.4. Equilibrium Stability: The Case of Strong Income Effects. To study the properties of equilibria we start by defining a steady state to be a pair of numbers $\{\bar{R}, \bar{b}\}$ that solves,

$$
\bar{b}=\bar{R} \cdot(\bar{b}+d) \quad S(\bar{R})=\bar{b}+d .
$$

It follows from inspection of equations (7) that, when $d=0$, there are two candidates for a steady state: either $\bar{R}=1$ or $\bar{b}=0$. The first of these is what David Gale (1973) calls the golden rule and the second is what he refers to as an autarkic equilibrium. In our analysis we will provide a calibrated model in which both of these steady states are locally stable. Further, we will show that when the government runs a budget surplus of the magnitude we have observed in US data, there is an equilibrium path of interest rates that automatically stabilizes the value of government debt without the need for fiscal reform.

To analyze the dynamics of the OLG model we use the bond market clearing condition (Equation 5 to define a correspondence $\phi: \mathbb{R}: \rightarrow \mathbb{R}_{+}$such that ${ }^{6}$

$$
R_{t+1}=\phi\left(b_{t}+d_{t}\right)
$$

Using the definition of $\phi$, we can rewrite Equation 3 as

$$
b_{t+1}=f\left(b_{t}, d\right)
$$

where

$$
f\left(b_{t}, d\right) \equiv \phi\left(b_{t}+d\right) \cdot\left(b_{t}+d\right)
$$

\footnotetext{
${ }^{6}$ If the aggregate savings function $S(\cdot)$ is invertible, then $\phi(\cdot)$ is simply defined as its inverse. In the case of strong income effects there will, however, exist multiple levels of the real interest rate $R_{t+1}$ clearing the bond market. While Figure 1 plots all of these values, formally we could have proceeded with local analysis and (uniquely) defined $\phi(\cdot)$ as the inverse of the branch containing the steady state.
} 


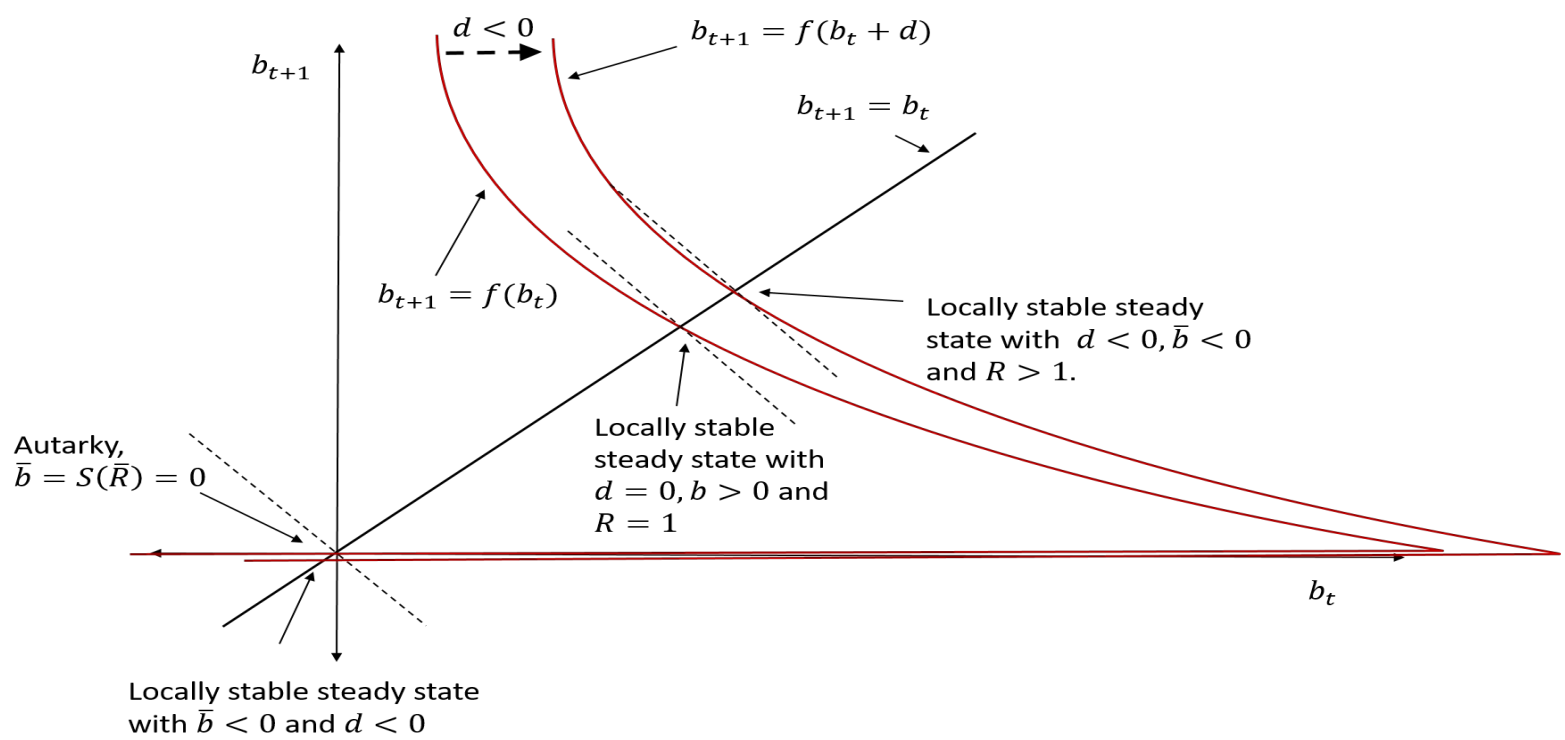

Figure 1. The Case of Strong Income Effects

Figure 1 illustrates the case of strong income effects. Under a calibration in which $S(1)>0$ both the golden rule and the autarkic steady state are locally stable. It is this property of local stability which allows the treasury to choose an active fiscal policy that is independent of the current value of government debt.

The figure also shows what happens when, starting from $d=0$, we lower the deficit and choose a negative value of $d$ in which the treasury commits to run a primary surplus: The corresponding value of the steady state interest rate, $\bar{R}$ becomes positive, as required by Condition 2$]^{7}$ Importantly, there exists a path for interest rates that converges asymptotically to the new steady state $\bar{b}_{\text {new }}$. On the figure $\bar{b}_{1}$ is represented by the locally stable steady state with $d=0$ and $R=1$ and $\bar{b}_{\text {new }}$ is the steady state with $d<0$ and $R>1$.

The parameters that we used to draw Figure 1 correspond to a calibration in which:

\begin{tabular}{c|c|c|c|c||c|c}
\hline \hline$\beta$ & $w^{2}$ & $d$ & $\tau$ & $\eta$ & $\bar{R}$ & $\bar{b}$ \\
\hline \hline 0.086 & 0.0125 & -0.02 & 0.15 & 0.091 & 1.06 & 0.38 \\
\hline \hline
\end{tabular}

Table 1: Strong Income Effects

In this case, we obtain the case of automatically-stabilizing debt discussed previously. The last two columns of Table 1 show that, in the steady state associated with a surplus of $2 \%$ of GDP, the equilibrium real interest factor is $\bar{R}=1.06$ and the debt to GDP ratio is $38 \%$.

Because we have only two generations, a period corresponds to approximately 40 years. A calibrated value for $\beta$ of 0.086 implies an annual discount factor of 0.94 which is close to

\footnotetext{
${ }^{7}$ The shift causes a parallel shift to the right of the equilibrium correspondence $f\left(b_{t}, d\right)$ as indicated. Proof that the corresponding $\bar{R}>1$ is provided in Section $\mathrm{B}$ of the Online Appendix.
} 
calibrations used in other studies. Further, the implied steady-state equilibrium interest factor of 1.06 implies an annual interest rate on treasuries of approximately one tenth of one percent. Since we abstract from growth, a real rate that is close to zero would correspond in a growing economy to an interest rate close to the growth rate, which is what we have seen in Post-WWII US data for the return to US treasury bills. Further, if the second period of life represents retirement, we can rationalize a relatively low value of $w^{2}$. This low value causes young people to hold substantial savings for retirement and ensures the strong income effects that are required to generate automatic stabilizers.

To conclude, we have provided a calibrated model using standard assumptions in which the government does not have to actively balance its budget. While our example is highly stylized, Farmer and Zabczyk (2018) show that a more complicated model with 70 generations retain all of the features discussed here. These numerical examples are thus robust illustrations of the fallacy of the household finance analogy 8

\section{Conclusion}

Macroeconomists are used to making arguments in the context of the representative agent model where the agent is the only counterparty to government borrowing. In this framework the demand for bonds is infinitely interest elastic and the real interest rate cannot adjust to stabilize government debt 9 By relying too heavily on this stylized representation, economists have perpetuated the household fallacy. We have shown in this note that the household fallacy is a feature of the infinitely-lived representative agent model that does not extend to more realistic demographics.

\footnotetext{
${ }^{8}$ In a Technical Appendix, available online, we show that our model can be recast as one in which debt is denominated in monetary units.

${ }^{9}$ The argument is formalized in the online Technical Appendix.
} 


\section{REFERENCES}

Azariadis, C. And R. Guesnerie (1986): "Sunspots and Cycles," The Review of Economic Studies, 53, 725-737.

BAlasko, Y. AND K. Shell (1981): "The overlapping-generations model. II. The case of pure exchange with money," Journal of Economic Theory, 24, 112-142.

Cass, D., M. Okuno, and I. Zilcha (1979): "The role of money in supporting the pareto optimality of competitive equilibrium in consumption-loan type models," Journal of Economic Theory, 20, 41-80.

Cochrane, J. (2018): "Deficits," The Grumpy Economist: Online Blog, Retrieved, February 28th 2018, https://johnhcochrane.blogspot.co.uk/2018/02/deficits.html.

Diamond, P. A. (1965): "National Debt in a Neoclassical Growth Model," The American Economic Review, 55, 1126-1150.

Eggertsson, G. B. And P. Krugman (2012): "Debt, Deleveraging, and the Liquidity Trap: A Fisher-Minsky-Koo Approach," The Quarterly Journal of Economics, 127, 1469-1513.

FARmer, R. And P. ZABCZyK (2018): "A requiem for the Fiscal Theory of the Price Level," Bank of England Staff Working Paper; forthcoming.

Farmer, R. E. A. (2012): "Confidence, Crashes and Animal Spirits," Economic Journal, 122.

Gale, D. (1973): "Pure exchange equilibrium of dynamic economic models," Journal of Economic Theory, 6, 12-36.

Geanakoplos, J. D. and H. M. Polemarchakis (1991): "Chapter 35 Overlapping generations," in Handbook of Mathematical Economics, ed. by W. Hildenbrand and H. Sonnenschein, Elsevier, vol. 4, 1899 - 1960.

Gourieroux, C., J. Laffont, And A. Monfort (1982): "Rational Expectations in Dynamic Linear Models: Analysis of the Solutions," Econometrica, 50, 409-425.

Grandmont, J.-M. (1985): "On Endogenous Competitive Business Cycles," Econometrica, 53, 995-1045.

Krugman, P. (2015): "The Austerity Delusion," The Guardian.

Leeper, E. M. (1991): “Equilibria Under 'Active' and 'Passive' Monetary and Fiscal Policies," Journal of Monetary Economics, 27, 129-147.

Samuelson, P. A. (1958): "An Exact Consumption-Loan Model of Interest with or without the Social Contrivance of Money," Journal of Political Economy, 66, 467.

Wolf, M. (2013): "How Austerity has Failed," The New York Review of Books. 


\section{THE HOUSEHOLD FALLACY ONLINE TECHNICAL APPENDIX}

\section{ROGER E.A. FARMER AND PAWEL ZABCZYK}

\section{Appendix A. Taxes and Fiscal Policy}

We start by formally introducing government spending and taxation. Letting $\tilde{w}^{1}$ and $\tilde{w}^{2}$ denote pre-tax, real endowments we assume real lump-sum tax obligations of $\tau^{1}$ on the young and $\tau^{2}$ on the old, such that

$$
\begin{aligned}
1 & =\tilde{w}^{1}-\tau^{1} \\
w^{2} & =\tilde{w}^{2}-\tau^{2} .
\end{aligned}
$$

Since taxes, like endowments, will be assumed time-invariant, the quantities of 1 and $w^{2}$ appearing in the consumers' maximization problem can be interpreted as after-tax endowments, with the consumers' optimization problem requiring no further modification.

\section{Appendix B. Steady States}

B.1. The balanced budget case $(d=0)$. When $d=0$ our setup is essentially the same as that considered by Samuelson (1958) and Gale (1973), with population growth set to zero and a constant relative risk aversion utility specification. A steady state of this model is a pair $(\bar{R}, \bar{b})$ such that

$$
\begin{gathered}
s^{1}(\bar{R})=1-\left(\frac{\bar{R}^{1-\eta}+w^{2} \bar{R}^{-\eta}}{\bar{R}^{1-\eta}+\beta^{\eta}}\right)=\bar{b} \\
\bar{b}=\bar{R} \bar{b} .
\end{gathered}
$$

Proposition 1. The system of steady state equations (B.1)-(B.2) has exactly two solutions. Using the terminology proposed in Samuelson (1958) and Gale (1973), these are: (i) the golden rule (GR) steady state, in which $\bar{R}^{G R}=1$ and $\bar{b}^{G R}=s^{1}$ (1) and (ii) the autarkic steady state, which has $\bar{b}^{A U}=0$ and $\bar{R}^{A U}$ solving $s^{1}\left(\bar{R}^{A U}\right)=0$. After plugging in and simplifying these can be shown to equal

$$
\left(\bar{R}^{G R}, \bar{b}^{G R}\right)=\left(1, \frac{\beta^{\eta}-w^{2}}{1+\beta^{\eta}}\right) \quad \text { and } \quad\left(\bar{R}^{A U}, \bar{b}^{A U}\right)=\left(\frac{\left(w^{2}\right)^{\frac{1}{\eta}}}{\beta}, 0\right) .
$$

Proof. The proof follows from the more general existence theorem in Gale (1973). Like Gale 1973 we assume away the coincidental case $\left(w^{2}\right)^{\frac{1}{\eta}}=\beta$ implying that there will always be two distinct steady states. The fact that the formulae above satisfy equations (B.1)-(B.2) completes the proof.

Corollary 2. A model is Samuelson (classical) iff $\beta^{\eta}>w^{2}\left(\beta^{\eta}<w^{2}\right)$.

Proof. Gale (1973) referred to a model as Samuelson (classical) if $\bar{c}^{1, G R}<1\left(\bar{c}^{1, G R}>1\right)$, which since $\bar{b}=1-\bar{c}^{1}$ translates into $\bar{b}^{G R}>0\left(\bar{b}^{G R}<0\right)$. The corollary then immediately follows from the formula for $\bar{b}^{G R}$ in Equation B.3. 
B.2. The general case (arbitrary $d$ ). We start with a Lemma.

Lemma 3. The solutions to

$$
f(\bar{R}) \equiv(1-\bar{R}) s^{1}(\bar{R})=d .
$$

uniquely characterize all admissible steady state values for $\bar{R}$.

Proof. We note that one of two cases is possible.

In the first $d=0$ and, as shown in Proposition $1 \bar{R}=1$ is one of two solutions to our system. Since the bond market accumulation equation implies $(1-\bar{R}) \bar{b}=\bar{R} d \Longrightarrow(1-\bar{R})(\bar{b}+d)=d$, therefore multiplying the bond market clearing condition by $(1-\bar{R})$ we are ensuring that the roots of $(1-\bar{R}) s^{1}(\bar{R})=0$ give us all the SS solutions for $\bar{R}$.

In the second case, when $d \neq 0 ; \bar{R}=1$ is not a solution to our system because it violates bond market accumulation. In this case, multiplying by $1-\bar{R}$ is like multiplying by a constant, hence also implies no loss of generality. This completes the proof.

This result will prove very helpful as the left hand side of Equation B.4 is continuous in $\bar{R}$, and in particular does not depend on the primary fiscal deficit $d$.

Lemma 4. The savings function $s^{1}(\bar{R})$ changes sign once. Letting $R^{*}$ denote the unique zero of the savings function, i.e. $s^{1}\left(R^{*}\right)=0$ we have $\forall R \leq R^{*}: s^{1}(R) \leq 0$ and $s^{1}(R) \geq 0$ otherwise.

Proof. The single sign change is a direct consequence of there being exactly two steady states for $d=0$ (characterized analytically in Proposition 1). From the definition of the savings function, Equation 4 we also know that

$$
s^{1}(\bar{R})=\frac{\beta^{\eta}-w^{2} \bar{R}^{-\eta}}{\bar{R}^{1-\eta}+\beta^{\eta}}
$$

and so, since the denominator is always positive (the domain is restricted to $\bar{R}>0$ ), therefore the sign is determined by the numerator. Because $\eta \geq 0$ therefore the numerator will be negative in the vicinity of 0 and strictly positive in $+\infty$. This concludes the proof.

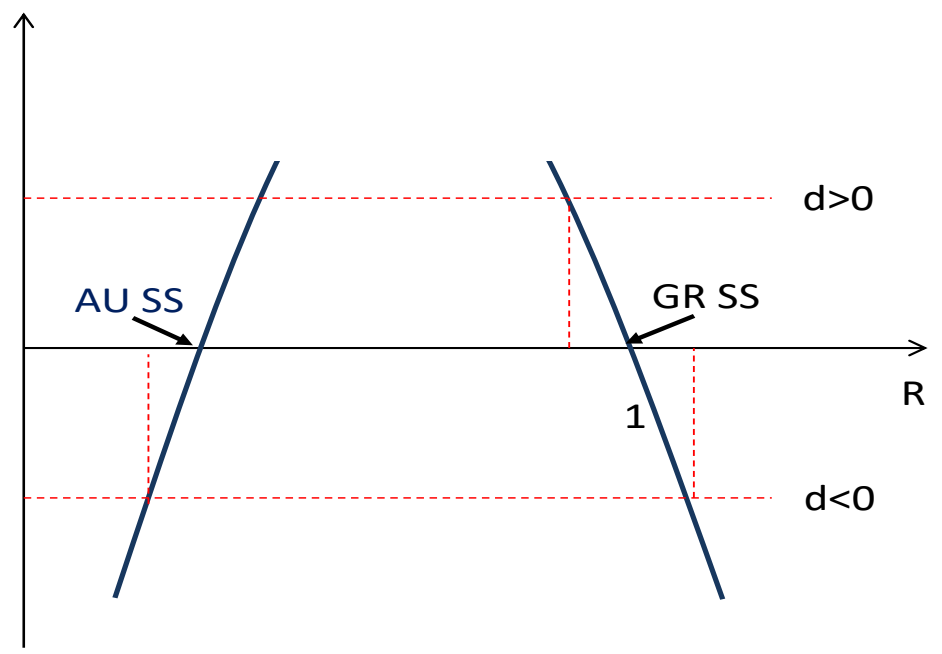

Figure 2. The function $f(\bar{R})=(1-\bar{R}) s^{1}(\bar{R})$ in the vicinity of the autarkic $(\mathrm{AU})$ and golden rule (GR) SS: 'Samuelson' calibration.

An immediate implication of Lemma 4 is that the behavior of the $f(\bar{R})$ function defined in Equation B.4 in the vicinity of the balanced and golden rule steady states for the 'Samuelson' 
calibration is as depicted in Figure 2 (note the presence of $(1-\bar{R})$ in the definition of $f(\bar{R})$ which additionally affects the sign). Crucially, the steady state real interest rates $\bar{R}$ for values of $d \neq 0$ correspond to intersections of the blue lines with the horizontal red-dashed line at $d$. The chart also makes clear why we shall refer to the new SSs as the 'shifted' autarkic and golden rule steady states. We can thus immediately read equilibrium values of $\bar{R}$ corresponding to small $d$ off the chart. Similarly, we can use Figure 1 to characterize equilibrium values of $\bar{b}$ corresponding to small $d$. Information that can be obtained by combining these two tools is summarized in the following proposition.

Proposition 5. All possible steady state combinations of $(\bar{R}, \bar{b})$ for (small) $d \gtreqless 0$ are characterized in Table 1.

\begin{tabular}{|c|c:c|c:ccc|}
\hline & \multicolumn{3}{|c|}{ Samuelson Case: $\beta^{\eta}>w^{2}$} & \multicolumn{3}{|c|}{ Classical Case: $\beta^{\eta}<w^{2}$} \\
\hline & $d<0$ & $d=0$ & $d>0$ & $d<0$ & $d=0$ & $d>0$ \\
\hline $\bar{R}^{A U}$ & $<1$ & $\left(\frac{w^{2}}{\beta^{\eta}}\right)^{\frac{1}{\eta}}<1$ & $<1$ & $>1$ & $\left(\frac{w^{2}}{\beta^{\eta}}\right)^{\frac{1}{\eta}}>1$ & $>1$ \\
$\bar{b}^{A U}$ & $<0$ & 0 & $>0$ & $>0$ & 0 & $<0$ \\
\hline \hline $\bar{R}^{G R}$ & $>1$ & 1 & $<1$ & $<1$ & 1 & $>1$ \\
$\bar{b}^{G R}$ & $+>\frac{\beta^{\eta}-w^{2}}{1+\beta^{\eta}}$ & $\frac{\beta^{\eta}-w^{2}}{1+\beta^{\eta}}>0$ & $+<\frac{\beta^{\eta}-w^{2}}{1+\beta^{\eta}}$ & $-<\frac{\beta^{\eta}-w^{2}}{1+\beta^{\eta}}$ & $\frac{\beta^{\eta}-w^{2}}{1+\beta^{\eta}}<0$ & $->\frac{\beta^{\eta}-w^{2}}{1+\beta^{\eta}}$ \\
\hline
\end{tabular}

TABLE 1. An overview of possible steady state values of bond holdings and the real interest rate for different calibrations and values of $d$.

In what follows, we shall focus attention on the 'shifted' golden rule steady state corresponding to $d<0$ and the Samuelson calibration (bottom two rows of the first column in Table 1), for which $\bar{R}>1$ and $\bar{b}>\left(\beta^{\eta}-w^{2}\right) /\left(1+\beta^{\eta}\right)>0$ - i.e. in steady state we will have a strictly positive level of savings and a strictly positive real (net) interest rate, satisfying Condition 2 for dynamic efficiency.

\section{Appendix C. Income And Substitution Effects}

One of the reasons why we proceed under CRRA utility is to show that our results do not hinge on 'exotic' aspects of the preference specification. Another advantage is that we can explicitly compute income and substitution effects of changes in $R_{t+1}$ on the consumption of the young $c_{t}^{1}$, and we can analyze how these depend on steady state asset holdings. We will show that income effects will be absent close to any steady state with zero holdings of government bonds (i.e., if $d=0$, in the vicinity of any balanced steady state).

C.1. Marshallian and Hicksian demand functions. To proceed, we pick the second period good as the numeraire. This is to fix attention and involves no loss of generality. We can then characterize the Marshallian and Hicksian demand functions.

Proposition 6. Letting $c_{t}^{1, M}\left(p_{1}, p_{2} ; e_{1}, e_{2} ; W^{2}\right)$ denote the Marshallian (uncompensated) demand function corresponding to prices of $p_{1}, p_{2}$, real endowments of $e_{1}$ and $e_{2}$ and wealth (in 
units of the second period numeraire) of $W^{2}$ we have

$$
c_{t}^{1, M}\left(p_{1}, p_{2} ; e_{1}, e_{2} ; W^{2}\right)=\frac{\frac{p_{1}}{p_{2}} e_{1}+\left(e_{2}+W^{2}\right)}{\frac{p_{1}}{p_{2}}+\left(\frac{p_{1}}{p_{2}} \beta\right)^{\eta}} .
$$

Proof. The proof follows directly from the formula for optimum consumption.

To use the Slutsky decomposition into income and substitution effects we will also need to define the Hicksian (compensated) demand function, which is characterized below.

Proposition 7. Letting $c_{t}^{1, H}\left(p_{1}, p_{2} ; U\right)$ be the Hicksian (compensated) demand function corresponding to prices of $p_{1}$ and $p_{2}$ and a utility level of $U$, we have

$$
c_{t}^{1, H}\left(p_{1}, p_{2} ; U\right)=\left(\frac{U \alpha+(1+\beta)}{1+\beta\left(\beta \frac{p_{1}}{p_{2}}\right)^{\eta-1}}\right)^{\frac{\eta}{\eta-1}} .
$$

Proof. The compensated demands $c_{t}^{1, H}, c_{t+1}^{2, H}$ are solutions to

$$
\min _{c_{t}^{1, H}, c_{t+1}^{2, H}} p_{1} c_{t}^{1, H}+p_{2} c_{t+1}^{2, H}
$$

where maximization is subject to

$$
\frac{\left(c_{t}^{1, H}\right)^{\alpha}+\beta\left(c_{t+1}^{2, H}\right)^{\alpha}-(1+\beta)}{\alpha}=U .
$$

The first two first-order conditions give us the familiar consumption Euler equation

$$
c_{t+1}^{2, H}=\left(\beta \frac{p_{1}}{p_{2}}\right)^{\eta} c_{t}^{1, H}
$$

which we can plug into the 'utility constraint' to find

$$
\left(c_{t}^{1, H}\right)^{\alpha} \frac{1+\beta\left(\beta \frac{p_{1}}{p_{2}}\right)^{\eta \alpha}}{\alpha}=U+\frac{1+\beta}{\alpha}
$$

Using $\eta=1 /(1-\alpha) \Longrightarrow \alpha=(\eta-1) / \eta$ which implies $\eta \alpha=\eta-1$ and $1 / \alpha=\eta /(\eta-1)$, and solving for $c_{t}^{1, H}$ then gives the required result.

C.2. The Slutsky Decomposition. We can now invoke the Slutsky Equation, in its version tailored to a setup with real endowments (see e.g. Silberberg (3rd edition), pp. 299 - 304) which states

$$
\begin{aligned}
\underbrace{\frac{\partial c_{t}^{1, M}\left(p_{1}, p_{2} ; e_{1}, e_{2} ; W^{2}\right)}{\partial p_{1}}}_{T E}=\underbrace{\frac{c_{t}^{1, H}\left(p_{1}, p_{2} ; U^{*}\right)}{\partial p_{1}}}_{S E} \\
\underbrace{-\frac{\partial c_{t}^{1, M}\left(p_{1}, p_{2} ; e_{1}, e_{2} ; W^{2}\right)}{\partial W^{2}}\left(c_{t}^{1, M}\left(p_{1}, p_{2} ; e_{1}, e_{2} ; W^{2}\right)-1\right)}_{I E}
\end{aligned}
$$

where the total effect of a change in real interest rates on consumption (LHS) is decomposed into the substitution effect (SE; first term on RHS) and the income effect (IE; second group of terms), and where $U^{*}$ is the level of utility corresponding to prices $p_{1}, p_{2}$, endowments $e_{1}$ and $e_{2}$ and wealth $W^{2}$. Crucially, we immediately see that the sign and size of the income effect 
will depend on the savings of the young, i.e. the difference between consumption in the initial period and the initial endowment of 1 .

To make the Slutsky decomposition directly applicable to our setup, we note that by choosing the second good as numeraire the respective derivatives will need to be evaluated at

$$
\left(p_{1}, p_{2} ; e_{1}, e_{2} ; W^{2}\right)=\left(R_{t+1}, 1 ; 1, w^{2} ; 0\right)
$$

which additionally highlights that the real interest rate $R_{t+1}$ is the only (relative) price in the model. Increases in $R_{t+1}$ make consumption in the second period cheaper in terms of consumption in period 1 - less has to be saved by the young to enjoy a unit of consumption when old - but they also increase income from the stock of saving $s^{1}\left(R_{t+1}\right)$ when the young are net savers. The first of these effects, the substitution effect, will tend to shift consumption into the future. The second of these effects, the income effect, would tend to increase consumption in both periods. Accordingly, the total effect of changes in $R_{t+1}$ on first period consumption, and hence also on total savings, is ambiguous and is determined by the respective sizes of both these effects. These are characterized in the proposition below.

Proposition 8. The substitution (SE) and income (IE) effects of a change in the real interest rate $R_{t+1}$ on the consumption of the young $c^{1}$ equal respectively

$$
\begin{aligned}
S E & =-\eta \beta^{\eta} R_{t+1}^{\eta-1} \frac{\left(R_{t+1}+w^{2}\right)}{\left(R_{t+1}+\left(R_{t+1} \beta\right)^{\eta}\right)^{2}} \\
I E & =-\frac{1}{R_{t+1}+\left(R_{t+1} \beta\right)^{\eta}}\left(c_{t}^{1, M}\left(R_{t+1}, 1 ; 1, w^{2} ; 0\right)-1\right) .
\end{aligned}
$$

Proof. Straight from the definition of Hicksian demand, the substitution effect equals

$$
\begin{aligned}
S E & \equiv \frac{\partial c_{t}^{1, H}\left(R_{t+1}, 1 ; U^{*}\right)}{\partial R_{t+1}}=\frac{\partial}{\partial R_{t+1}}\left(\frac{U^{*} \alpha+(1+\beta)}{1+\beta\left(\beta R_{t+1}\right)^{\eta-1}}\right)^{\frac{\eta}{\eta-1}} \\
& =-\frac{\eta}{\eta-1}\left(\frac{U^{*} \alpha+(1+\beta)}{1+\beta\left(\beta R_{t+1}\right)^{\eta-1}}\right)^{\frac{1}{\eta-1}} \frac{U^{*} \alpha+(1+\beta)}{\left(1+\beta\left(\beta R_{t+1}\right)^{\eta-1}\right)^{2}} \beta(\eta-1)\left(\beta R_{t+1}\right)^{\eta-2} \beta \\
& =-\eta\left(\frac{U^{*} \alpha+(1+\beta)}{1+\beta\left(\beta R_{t+1}\right)^{\eta-1}}\right)^{\frac{\eta}{\eta-1}} \frac{\beta^{\eta} R_{t+1}^{\eta-2}}{1+\beta\left(\beta R_{t+1}\right)^{\eta-1}}=-\eta \beta^{\eta} R_{t+1}^{\eta-1} \frac{\left(R_{t+1}+w^{2}\right)}{\left(R_{t+1}+\left(R_{t+1} \beta\right)^{\eta}\right)^{2}}
\end{aligned}
$$

where we have used the fact that the Hicksian demand function evaluated at $U^{*}$ (the first term in brackets in the final line) is identically equal to Marshallian demand, i.e.

$$
\left(\frac{U^{*} \alpha+(1+\beta)}{1+\beta\left(\beta R_{t+1}\right)^{\eta-1}}\right)^{\frac{\eta}{\eta-1}}=\frac{R_{t+1}+w^{2}}{R_{t+1}+\left(R_{t+1} \beta\right)^{\eta}} .
$$

The income effects can then be computed as

$$
\begin{aligned}
I E & \equiv-\frac{\partial c_{t}^{1, M}\left(R_{t+1}, 1 ; 1, w^{2} ; W^{2}\right)}{\partial W^{2}}\left(c_{t}^{1, M}\left(R_{t+1}, 1 ; 1, w^{2} ; W^{2}\right)-1\right) \\
& =-\frac{1}{R_{t+1}+\left(R_{t+1} \beta\right)^{\eta}}\left(c_{t}^{1, M}\left(R_{t+1}, 1 ; 1, w^{2} ; W^{2}\right)-1\right)
\end{aligned}
$$

which completes the proof. 


\section{Appendix D. Dynamic Properties of the Model}

Having characterized the steady states and having discussed the importance of the interplay between income and substitution effects we now proceed to formally analyze the stability of the golden rule steady state for $d=0$. By continuity, the dynamic properties of this steady state will remain unchanged for small values of $d$.

For the purpose of linearizing we first define

$$
\begin{aligned}
& \forall t \geq 1: f^{1}\left(b_{t}, R_{t+1}\right) \equiv s^{1}\left(R_{t+1}\right)-b_{t}-d \\
& \forall t \geq 1: f^{2}\left(b_{t}, b_{t+1}, R_{t+1}\right) \equiv b_{t+1}-R_{t+1}\left(b_{t}+d\right)
\end{aligned}
$$

with the savings function $s^{1}(\cdot)$ defined in Equation 4. A linear approximation around the steady state is

$$
\begin{aligned}
& \forall t \geq 1: f^{1}\left(b_{t}, R_{t+1}\right) \equiv f_{b}^{1} \cdot\left(b_{t}-\bar{b}\right)+f_{R(+1)}^{1} \cdot\left(R_{t+1}-\bar{R}\right) \\
& \forall t \geq 1: f^{2}\left(b_{t}, b_{t+1}, R_{t+1}\right) \equiv f_{b}^{2} \cdot\left(b_{t}-\bar{b}\right)+f_{b(+1)}^{2} \cdot\left(b_{t+1}-\bar{b}\right)+f_{R(+1)}^{2} \cdot\left(R_{t+1}-\bar{R}\right)
\end{aligned}
$$

where all the derivatives are evaluated in the steady state.

In matrix form this can be written as

$$
\forall t \geq 1:\left[\begin{array}{c}
\left(R_{t+1}-\bar{R}\right) \\
\left(b_{t+1}-\bar{b}\right)
\end{array}\right]=J \cdot\left[\begin{array}{c}
\left(R_{t}-\bar{R}\right) \\
\left(b_{t}-\bar{b}\right)
\end{array}\right]
$$

where

$$
J=\left[\begin{array}{ll}
f_{R(+1)}^{1} & 0 \\
f_{R(+1)}^{2} & f_{b(+1)}^{2}
\end{array}\right]^{-1}\left[\begin{array}{ll}
0 & -f_{b}^{1} \\
0 & -f_{b}^{2}
\end{array}\right] .
$$

With one exception, all the derivatives in $J$ are easy to find. Specifically

$$
f_{b}^{2}=-\bar{R} \quad f_{b(+1)}^{2}=1 \quad f_{R(+1)}^{2}=-(\bar{b}+d) \quad f_{b}^{1}=-1
$$

which implies that

$$
\begin{aligned}
J & =\left[\begin{array}{ll}
f_{R(+1)}^{1} & 0 \\
-(\bar{b}+d) & 1
\end{array}\right]^{-1}\left[\begin{array}{ll}
0 & 1 \\
0 & \bar{R}
\end{array}\right] \\
& =\left[\begin{array}{ll}
\frac{1}{f_{R(+1)}^{1}} & 0 \\
\frac{1}{f_{R(+1)}^{1}}(\bar{b}+d) & 1
\end{array}\right]\left[\begin{array}{ll}
0 & 1 \\
0 & \bar{R}
\end{array}\right]=\left[\begin{array}{ll}
0 & \frac{1}{f_{R(+1)}^{1}} \\
0 & \frac{1}{f_{R(+1)}^{1}}(\bar{b}+d)+\bar{R}
\end{array}\right]
\end{aligned}
$$

and so our dynamic equation is

$$
\forall t \geq 1:\left[\begin{array}{c}
\left(R_{t+1}-\bar{R}\right) \\
\left(b_{t+1}-\bar{b}\right)
\end{array}\right]=\left[\begin{array}{ll}
0 & \frac{1}{f_{R(+1)}^{1}} \\
0 & \frac{1}{f_{R(+1)}^{1}}(\bar{b}+d)+\bar{R}
\end{array}\right] \cdot\left[\begin{array}{l}
\left(R_{t}-\bar{R}\right) \\
\left(b_{t}-\bar{b}\right)
\end{array}\right] .
$$

We immediately note that the choice of $R_{1}$ is inconsequential. The values of $R_{2}$ and $b_{2}$ only depend on $b_{1}$, itself an initial condition. Accordingly, the steady state will be stable if and only if both eigenvalues of $J$ lie within the unit circle. The eigenvalues are roots of the characteristic polynomial

$$
\left|\begin{array}{ll}
-\lambda & \frac{1}{f_{R(+1)}^{1}} \\
0 & \frac{1}{f_{R(+1)}^{1}}(\bar{b}+d)+\bar{R}-\lambda
\end{array}\right|=-\lambda\left(\frac{1}{f_{R(+1)}^{1}}(\bar{b}+d)+\bar{R}-\lambda\right) .
$$


We immediately see that the first eigenvalue is always equal to zero, while the other will depend on the properties of $f_{R(+1)}^{1}$ if and only if $\bar{b}+d \neq 0$. This re-iterates the importance of non-zero steady state bond holdings. Specifically, if $\bar{b}+d=0$ then the steady state would be unstable whenever $\bar{R}>1$ i.e. in all the economically interesting situations. Instead, the case we highlight is one in which $\bar{b}+d>0$ and $\left(f_{R(+1)}^{1}\right)^{-1}<0$ which helps ensure that $\left(f_{R(+1)}^{1}\right)^{-1}(\bar{b}+d)+\bar{R}$ lies within the unit circle, ensuring steady state stability.

Unsurprisingly, the exact condition guaranteeing that

$$
\left|\frac{\bar{b}^{G R}}{f_{R(+1)}^{1}}+\bar{R}^{G R}\right|<1
$$

is equivalent to one ensuring that income effects exceed substitution effects. This is characterized analytically in Proposition 9.

Proposition 9. The Golden Rule Steady State in Samuelson's calibration is stable if and only if

$$
\alpha<-\frac{\left(1+\beta^{\eta}\right)}{\left(1-\beta^{\eta}\right)} \frac{\left(\beta^{\eta}+w^{2}\right)}{\left(\beta^{\eta}-w^{2}\right)}
$$

Proof. The first condition we require for stability is $f_{R(+1)}^{1}<0$-i.e. we want savings to decrease as interest rates increase. The derivative of the savings function has already been characterized when discussing income and substitution effects and equals

$$
f_{R(+1)}^{1}=\frac{\partial s^{1}\left(R_{t+1}\right)}{\partial R_{t+1}}=-\frac{R_{t+1}+(\beta R)^{\eta}-\left(R_{t+1}+w^{2}\right)\left(1+\eta \beta^{\eta} R_{t+1}^{\eta-1}\right)}{\left(R_{t+1}+\beta^{\eta} R_{t+1}^{\eta}\right)^{2}}
$$

and so, in particular, its sign will be determined by the numerator. This, in the Golden Rule Steady State (where $\bar{R}=1$, and where we evaluate the derivative), equals

$$
-\left(1+\beta^{\eta}\right)+\left(1+w^{2}\right)\left(1+\eta \beta^{\eta}\right) .
$$

The derivative is negative, implying an eigenvalue smaller than one, if and only if

$$
\left(1+w^{2}\right)\left(1+\eta \beta^{\eta}\right)<\left(1+\beta^{\eta}\right) .
$$

which is equivalent to

$$
\alpha<-w^{2} \frac{\beta^{\eta}+1}{\beta^{\eta}-w^{2}} .
$$

We additionally want to make sure that the eigenvalue is not smaller than -1 , i.e.

$$
\frac{s^{1}(1)}{f_{R(+1)}^{1}}>-2
$$

Since $f_{R(+1)}^{1}$ is negative therefore this is equivalent to

$$
\begin{gathered}
s^{1}(1)<-2 f_{R(+1)}^{1} \Uparrow \\
\alpha<\frac{-w^{2}-\beta^{2 \eta}-\beta^{\eta}-\beta^{\eta} w^{2}}{\left(1-\beta^{\eta}\right)\left(\beta^{\eta}-w^{2}\right)}=\frac{-w^{2}\left(1+\beta^{\eta}\right)-\beta^{\eta}\left(1+\beta^{\eta}\right)}{\left(1-\beta^{\eta}\right)\left(\beta^{\eta}-w^{2}\right)}
\end{gathered}
$$

which is the the required result. Because

$$
\frac{s^{1}(1)}{f_{R(+1)}^{1}}>-2 \Longleftrightarrow s^{1}(1)<-2 f_{R(+1)}^{1} \Longleftrightarrow f_{R(+1)}^{1}<\frac{s^{1}(1)}{-2} \Longrightarrow f_{R(+1)}^{1}<0
$$


therefore a necessary and sufficient condition is simply the last one, which completes the proof.

\section{Appendix E. The Monetary Extension}

Aside from being very stylized, our OLG model is purely real, potentially raising questions about the relevance of the automatic stabilizer mechanism in economies where fiat money has value. We therefore now show how the model can be reinterpreted as the cashless limit of an economy with nominal government debt, where monetary policy is constrained by the zero lower bound.

In the nominal OLG model the government continues to purchase $g_{t}$ units of a consumption good in period $t$ which is financed from lump-sum taxes and through issuance of nominal debt. Each government bond has a face value of one dollar. $B_{t}$ denotes the number of bonds issued at time $t$ and $B_{t-1}$ represents the dollar value of debt to be repaid at time $t$. $Q_{t}$ denotes the time $t$ dollar bond price. Proceeds from debt issuance $Q_{t} B_{t}$ and lump-sum tax revenues $p_{t} \tau_{t}$ are used to pay $B_{t-1}$ to holders of government bonds issued in period $t-1$ and to purchase $g_{t}$ for $p_{t} g_{t}$ dollars. Here $p_{t}$ denotes the price of the consumption good in dollars, which serves as the unit of account. The government budget constraint, or debt accumulation equation, is

$$
Q_{t} B_{t}+p_{t} \tau_{t}=B_{t-1}+p_{t} g_{t} \quad \Leftrightarrow \quad \frac{Q_{t} B_{t}-B_{t-1}}{p_{t}}=d_{t}
$$

where the primary fiscal deficit continues to be defined as in Equation 2, Letting $b_{t}$ i.e. the real value of government debt maturing at time $t$ equal

$$
b_{t} \equiv \frac{B_{t-1}}{p_{t}}
$$

we can rewrite the government budget constraint as

$$
\frac{1}{1 / Q_{t}} \frac{p_{t+1}}{p_{t}} \frac{B_{t}}{p_{t+1}}-\frac{B_{t-1}}{p_{t}}=\frac{1}{1 / Q_{t}} \frac{p_{t+1}}{p_{t}} b_{t+1}-b_{t}=d_{t} .
$$

Define the inflation factor by the identity $\Pi_{t+1} \equiv p_{t+1} / p_{t}$, and note that the nominal interest rate $i_{t}$ is linked to the bond price, $Q_{t}$, via the expression $1+i_{t} \equiv 1 / Q_{t}$. Using these relations, we may combine the Fisher parity equation $R_{t+1} \equiv\left(1+i_{t}\right) / \Pi_{t+1}$ with the assumption that the nominal interest rate is zero to arrive at a restatement of the government debt accumulation equation in purely real terms,

$$
\forall t \geq 1: b_{t+1}=R_{t+1}\left(b_{t}+d_{t}\right) .
$$

This matches Equation 3. It is straightforward to show that the bond market clearing condition obtained from a modified utility maximization problem

$$
\begin{gathered}
\max _{c_{t}, c_{t+1}} \frac{c_{t}^{\alpha}+\beta c_{t+1}^{\alpha}-(1+\beta)}{\alpha} \\
\text { s.t.: } p_{t} c_{t}+p_{t+1} c_{t+1}=p_{t}+p_{t+1} w^{2}
\end{gathered}
$$

exactly matches Equation 5 . We have shown that the more descriptively realistic nominal model yields the exact same market clearing conditions, and hence the same dynamics for real variables as the model discussed in the body of the note. 


\section{Appendix F. Government Debt in a Representative Agent Setup}

We conclude by highlighting that the household fallacy is hard-wired into the infinitely-lived representative agent model. This is because, on the one hand, the representative agent is the only counterparty to government borrowing and so more debt makes her richer. On the other hand, the government can only service higher debt by levying more taxes on the representative agent which exactly offsets any positive effects. As a consequence, bond demand is infinitely elastic, implying a vertical aggregate demand schedule $S(\cdot)$ and ensuring that real rates are no longer free to stabilize government debt.

To formally prove this result, consider the consumption-Euler equation in the RA setup,

$$
\forall t \geq 1: C_{t}^{-\eta}=\beta C_{t+1}^{-\eta} R_{t+1} .
$$

Let $Y_{t}$ represent the aggregate endowment. When the aggregate endowment and government purchases, $g_{t}$ are constant, goods market clearing implies

$$
\forall t \geq 1: R_{t+1}=\frac{1}{\beta} \frac{(Y-g)^{-\eta}}{(Y-g)^{-\eta}}=\frac{1}{\beta}
$$

i.e. the real interest rate is pinned down by the inverse of the rate of time preference 10 Accordingly, Equation 6 would now state

$$
b_{1}=-\sum_{t=1}^{+\infty} \frac{d_{t}}{\beta^{1-t}} .
$$

It follows that if the world was like a representative agent endowment economy then John Boehner would have been right: if $b_{1}$ happened to be such that the equation above held, then an increase in initial government debt $b_{n e w}>b_{1}$ would have to be offset by a plan to increase taxes or reduce expenditure, i.e. by 'passive' adjustment in $d_{t}$ at some date(s) in the future.

This fact is not a legitimate justification of the household fallacy; rather it is an unrealistic feature of the RA model. We have shown that, in the OLG model, the burden of debt repayment from old to young can ensure that changes in debt levels affect the young agents' propensity to save. In our calibrated example the bond demand schedule is interest-elastic, and equilibrium variations in the demand for bonds allow the real interest rate to act as an automatic stabilizer.

\footnotetext{
${ }^{10}$ It is important to note that, even if we had allowed for stochastic fluctuations in the endowment, or for aggregate investment and a non-zero capital stock, these modifications would not alter the fact that, in the RA model, the real rate dynamics do not depend on the level of government debt.
} 